\title{
Dénouement des Lumières et invention romantique, textes réunis par Giovanni Bardazzi et Alain Grosrichard
}

\section{Eric Francalanza}

\section{(2) OpenEdition}

1 Journals

\section{Édition électronique}

URL : http://journals.openedition.org/studifrancesi/36267

DOI : $10.4000 /$ studifrancesi.36267

ISSN : 2421-5856

\section{Éditeur}

Rosenberg \& Sellier

\section{Édition imprimée}

Date de publication : 1 juillet 2005

Pagination : 173-174

ISSN : 0039-2944

\section{Référence électronique}

Eric Francalanza, «Dénouement des Lumières et invention romantique, textes réunis par Giovanni Bardazzi et Alain Grosrichard », Studi Francesi [En ligne], 145 (XLIX | I) | 2005, mis en ligne le 30 novembre 2015, consulté le 19 avril 2021. URL : http://journals.openedition.org/studifrancesi/36267 ; DOI : https://doi.org/10.4000/studifrancesi.36267

Ce document a été généré automatiquement le 19 avril 2021.

\section{cc) $(9)$}

Studi Francesi è distribuita con Licenza Creative Commons Attribuzione - Non commerciale - Non opere derivate 4.0 Internazionale. 


\title{
Dénouement des Lumières et invention romantique, textes réunis par Giovanni Bardazzi et Alain Grosrichard
}

\author{
Eric Francalanza
}

\section{RÉFÉRENCE}

AV. VV., Dénouement des Lumières et invention romantique, textes réunis par GIOVANNI BARDAZZI et ALAIN GROSRICHARD, Genève, Droz, 2003 («Histoire des idées et critique littéraire»), pp. 384.

1 L'ouvrage se compose des actes du colloque tenu à Genève les 24 et 25 novembre 2000. Il se veut la continuation du volume, publié dans la même collection, Letteratura italiana et cultura europea tra Illuminismo et Romanticismo, dirigé par GUIDO SANTATO, en 2003. S'il comprend majoritairement des contributions en français, on en compte aussi quatre en italien.

2 Il paraît évident que le lien, exprimé dans le titre, entre Lumières et Romantisme, repose à la fois sur l'idée d'une européanisation des Lumières françaises et d'une interprétation de la Révolution de 1789 qui dépasse très vite les frontières de la France. Aussi le livre s'ouvre-t-il par un chapitre qui interroge les sources d'une histoire romantique en en traitant les divers aspects: politique et idéologique (Bronislaw BACZKO, pp. 11-18, Giovanni BARDAZZI, pp. 87-113 et Christian-Alain MÜLLER, pp. 19-46), philosophique (Emma TIEFFENBACH, pp. 47-67) et esthétique (Carine FLÜCKINGER, pp. 69-85). Informée dans une poétique qui lui donne une existence littéraire, la mutation qui s'opère à partir des années 1770 se lit aussi dans la «continuité» et les «transformations» des genres. On pourrait certes regretter que cette pluralité ne soit pas suffisamment prise en compte: quatre contributions, sur les cinq de ce second 
volet, sont en effet consacrées à la poésie; la dernière propose une enquête claire et intéressante sur les textes dédicatoires dans la littérature italienne (Maria-Antonietta TERZOLI, pp. 161-192). Cela dit, cette restriction du champ générique s'explique assez bien pour qui songe que le XVIII ${ }^{e}$ siècle fut une période d'intense réflexion sur le sens du langage et de la poésie. C'est pourquoi les études explorent des variations fondamentales dans l'expression et l'évolution du lyrisme français et espagnol (Jean STAROBINSKI, pp. 117- 130, François JACOB, pp. 131-142, Jenaro TALENS, pp. 193-203), ainsi que le domaine moins connu de la poésie didactique et scientifique (Luca DANZI, pp. 143-160). Trois chapitres proposent enfin, selon des perspectives différentes («Texte et image», pp. 206-260, «Le Regard sur l'autre», pp. 261-298, et «Approches de la subjectivité», pp. 299-367), une réflexion sur la question du «sujet», lato sensu. En art, elle s'ouvre autant à la production qu'à la critique, avec des articles très documentés sur Füssli (Luisa CALE, pp. 231-246) et sur Valenciennes (Elisabeth LAVEZZI, pp. 207-230). Toutefois, le domaine de l'image ne s'arrête pas à l'art: le Lavater portatif montre, par exemple, comment la sécularisation d'une œuvre permet d'entrer dans une enquête sur les mentalités et de lire un imaginaire populaire (Hans-Georg VON ARBURG, pp. 247-260). Mais les transpositions affectent aussi les représentations nationales, qu'elles s'informent dans l'œuvre littéraire (Saba BAHAR, pp. 263-276) ou, d'une manière plus large, dans une xénophilie/-phobie particulière (Antonio STAUBLE, pp. 277-298). Enfin, le domaine de la subjectivité est abordé à travers trois perspectives riches de suggestions: la naissance de la psychiatrie (Juan RIGoLI, pp. 301-320), l'amour et la question de l'individu (Verena EHRICH-HAEFELI, pp. 321-352), le sentiment religieux et son expression chez Constant (Markus WinkLER, pp. 353-367).

Il n'est pas besoin d'être grand clerc pour saisir à la fois la diversité des sujets et la difficulté de la question. De reste, l'unité du volume ne se dégage pas très nettement, et les éditeurs en sont conscients. Nous ne sommes d'ailleurs pas toujours bien convaincu par les méthodes d'approche dont le substrat théorique tend à faire de certains articles d'habiles compositions, parfois malheureusement assez lourdes. Pour quelques contributions, il eût été également bon d'en réviser plus précisément le français. Mais ces remarques ne doivent pas faire oublier, outre l'index fort appréciable, l'intérêt de la plupart des articles. 